\title{
Transmissibility of the Ice Bucket Challenge among globally influential celebrities: retrospective cohort study
}

\author{
(c) (1) (丹) OPEN ACCESS
}

\section{Michael Y Ni clinical assistant professor, Brandford H Y Chan research officer, Gabriel M Leung chair professor, Eric H Y Lau assistant professor, Herbert Pang assistant professor}

School of Public Health, Li Ka Shing Faculty of Medicine, The University of Hong Kong, Hong Kong Special Administrative Region, China

\begin{abstract}
Objectives To estimate the transmissibility of the Ice Bucket Challenge among globally influential celebrities and to identify associated risk factors.

Design Retrospective cohort study.

Setting Social media (YouTube, Facebook, Twitter, Instagram).

Participants David Beckham, Cristiano Ronaldo, Benedict Cumberbatch, Stephen Hawking, Mark Zuckerberg, Oprah Winfrey, Homer Simpson, and Kermit the Frog were defined as index cases. We included contacts up to the fifth generation seeded from each index case and enrolled a total of 99 participants into the cohort.
\end{abstract}

Main outcome measures Basic reproduction number $\mathrm{R}_{0}$, serial interval of accepting the challenge, and odds ratios of associated risk factors based on fully observed nomination chains; $R_{0}$ is a measure of transmissibility and is defined as the number of secondary cases generated by a single index in a fully susceptible population. Serial interval is the duration between onset of a primary case and onset of its secondary cases.

Results Based on the empirical data and assuming a branching process we estimated a mean $R_{0}$ of 1.43 (95\% confidence interval 1.23 to 1.65 ) and a mean serial interval for accepting the challenge of 2.1 days (median 1 day). Higher log (base 10) net worth of the participants was positively associated with transmission (odds ratio $1.63,95 \%$ confidence interval 1.06 to 2.50), adjusting for age and sex.

Conclusions The Ice Bucket Challenge was moderately transmissible among a group of globally influential celebrities, in the range of the pandemic A/H1N1 2009 influenza. The challenge was more likely to be spread by richer celebrities, perhaps in part reflecting greater social influence.

\section{Introduction}

The Ice Bucket Challenge, a campaign to raise awareness and support for people with amyotrophic lateral sclerosis, ${ }^{1}$ is widely recognised to have gone socially viral. Although there are variations to the trial, participants typically complete the challenge (they are doused in ice water or make a donation) and nominate three others to undertake it. ${ }^{2}$ As of 1 September 2014, more than 17 million videos related to the Ice Bucket Challenge were shared on Facebook alone, and these were viewed more than 10 billion times by more than 440 million people. ${ }^{3}$ Socially viral phenomena include videos that are made popular by sharing on the internet, and a video is said to have gone viral if it spreads rapidly as a result of frequent sharing. ${ }^{45}$ However, the infectious disease modelling framework has seldom been used to quantify the transmissibility of such socially viral phenomena. ${ }^{6}$ The most commonly used metric of transmissibility is the basic reproduction number $\left(\mathrm{R}_{0}\right)$, defined as the number of secondary cases generated by a single index in a fully susceptible population. ${ }^{7}$ The value of $R_{0}$ is a major determinant of the size of an epidemic, and an infection can only be self sustaining if $\mathrm{R}_{0}$ is greater than 1 . The $\mathrm{R}_{0}$ also provides a measure of the effort required to control the epidemic. ${ }^{78}$ We estimated the transmissibility of the Ice Bucket Challenge among globally influential celebrities and identified the associated risk factors.

\section{Methods}

\section{Participants}

We considered globally influential celebrities who had undertaken the Ice Bucket Challenge to be eligible for inclusion. 
Global influence was defined by the criteria: listed in TIME 100: The Most Influential People in the World or TIME: Great People of the 20th Century, ${ }^{10}$ or having at least five million view counts for the Ice Bucket Challenge on YouTube. Among the small pool of potentially eligible participants we arbitrarily chose David Beckham, Cristiano Ronaldo, Benedict Cumberbatch, Stephen Hawking, Mark Zuckerberg, Oprah Winfrey, Homer Simpson, and Kermit the Frog as index cases (table $1 \Downarrow$ ). We also included successful nominations up to the fifth generation seeded from each index case.

\section{Data collection}

We completed a marathon viewing of 145 Ice Bucket Challenges up to 13 September 2014. For each case we recorded the age, sex, occupation, net worth, popularity (proxied by number of likes on Facebook and number of Twitter followers), number of successful nominations, and total number of nominations. We obtained personal details of the celebrities from Wikipedia and specialised websites, although the validity of such information cannot be reliably ascertained. ${ }^{11}$ Wikipedia has been used in previous studies ${ }^{12}{ }^{13}$ and its comparative accuracy has been reported. ${ }^{14}$ From verified accounts we obtained the number of Facebook likes and Twitter followers. Where these were not available, we used the unofficial accounts with the most likes or followers. We excluded unofficial accounts with fewer than 1000 likes or followers.

We traced contacts through Google, YouTube, Facebook, Twitter, and Instagram. Online written or video responses by the nominated contacts were used to determine completion of the challenge. If we found no evidence for a response to the challenge on social media, it was assumed that the contact had declined. We included all successful contacts. Two of the authors (MYN, BHYC) independently collected the data. After the fifth generation seeded from each index case they stopped data collection owing to investigator fatigue. We did not seek previous consent from participants as they presumably participated in the Ice Bucket Challenge without coercion, albeit with varying degrees of peer and social pressure.

\section{Statistical analysis}

We used fully observed nomination chains to estimate the $\mathrm{R}_{0}$, a measure of transmissibility, for a celebrities based cohort, up to the fifth generation seeded from each index case (the first generation). $\mathrm{R}_{0}$ was estimated as the product of the mean number of nominations $(n)$ and the probability of successful nomination $(p)$, assuming a branching process in which each participant of the Ice Bucket Challenge generates a random number of next generation participants. To account for the fact that the challenge had already taken off in early August $2014,{ }^{15}$ we excluded nominees in the calculation of $p$ who had previously completed the challenge (that is, were "immune" from future participation) but included them in the calculation of $n$ so that the estimated $\mathrm{R}_{0}$ would reflect the transmissibility in a fully "susceptible" population. We obtained $95 \%$ confidence intervals of the $R_{0}$ estimate by bootstrap with 1000 replications. Mean serial interval was calculated by assuming at least a half day delay in accepting the challenge, based on all nominator-nominee pairs in our dataset. We used multivariable ordinal logistic regression to examine the association between number of successful nominations and personal factors (age, sex, occupation, and net worth) or popularity (number of likes on Facebook and number of followers on Twitter). To handle missing data we carried out sensitivity analysis with multiple imputation. All analyses were done using R version 3.0.2 and SAS university edition, 2014.

\section{Results}

Eight index cases complied with the inclusion criteria. In total we included 91 nominees up to the fifth generation seeded from each index case, and a total of 99 participants were enrolled into the cohort. Overall, $24.2 \%$ of participants had zero successful nominations, $32.3 \%$ had one, $26.3 \%$ had two, and $17.2 \%$ had three. Twelve (4.9\%) out of the 247 nominations had already participated in the Ice Bucket Challenge and were therefore "immune" from future participation. Among those observed were a Nobel laureate, a university vice chancellor, "heart throbs", and Muppets (both the actors and the puppets). Among the index cases, Mark Zuckerberg's nomination chain produced the most successful number of contacts (total of 41) up to the fifth generation (figure $\downarrow$ ). No serious adverse events arising from the Ice Bucket Challenge act were observed in this series, but adverse events have been reported elsewhere, ${ }^{16}$ including falls, head injuries, a temporomandibular joint dislocation, cuts, and at least one fatality. We estimated the measure of transmissibility, $\mathrm{R}_{0}$, to be 1.43 ( $95 \%$ confidence interval 1.23 to 1.65 ) and a mean serial interval of accepting the challenge of 2.1 days (median 1 day). We excluded Homer Simpson and Kermit the Frog in the regression models because of difficulty in ascertaining their personal characteristics. Participants with a higher log (base 10) net worth were more likely to spread the Ice Bucket challenge (odds ratio 1.63, 95\% confidence interval 1.06 to 2.50 ), adjusted for age and sex. One unit change on a $\log$ (base 10) scale is equivalent to a 10-fold change in net worth. We tested the proportional odds assumption for the regression model and found no indication of violation. Age, sex, occupation, number of Facebook likes, or number of Twitter followers were not associated with transmissibility (table $2 \Downarrow$ ). Data were missing for $24.0 \%$ of net worth, $15.6 \%$ of Facebook likes, and $13.5 \%$ of Twitter followers. Sensitivity analysis by multiple imputation yielded similar results (not shown).

\section{Discussion}

The Ice Bucket Challenge-a campaign to raise awareness and support for people with amyotrophic lateral sclerosis by dousing oneself with a bucket of iced water or giving a donation-was moderately transmissible among a group of globally influential celebrities. The celebrities took a mean 2.1 days (median 1 day) to accept the challenge (the serial interval). Our finding of an $\mathrm{R}_{0}$ value greater than unity (1.43), indicating sustained spread, in a celebrities based cohort is consistent with observations reported in the press. Indeed this social viral pandemic shares a similar $\mathrm{R}_{0}$ with pandemic A/H1N1 2009 influenza, or the high end of the Middle East respiratory coronavirus since 2012 (table $3 \Downarrow)$. Nine out of the 99 participants $(9.1 \%)$ completed the challenge but did not nominate anyone, analogous to self isolation. We included these participants in our analyses and assumed all losses to follow-up to have declined the challenge. As with other microbial pathogens, transmissibility of the Ice Bucket Challenge may also exhibit seasonal variation, ${ }^{17}$ where it might be anticipated that the $\mathrm{R}_{0}$ value would decrease during winter.

Possible factors accounting for the speed and extent of the Ice Bucket Challenge pandemic may include the online social media mode of transmission and the short serial interval for taking up the challenge (table 3 ). Despite a lower $\mathrm{R}_{0}$ than for measles or smallpox, the Ice Bucket Challenge spread quickly across the world as nominees became immediately "infectious" once nominated. A previous social network experiment found that individual uptake improved with reinforcing signals from clustered social ties. ${ }^{18}$ Therefore, specified nominations within 
a social network, such as celebrities, may be more successful in spreading promotional messages for public health interventions than are generic nominations. However, whether such social networks should be leveraged for health communication depends on the nature of the intervention. ${ }^{19}$ Finally, our findings suggest that the $\mathrm{R}_{0}$ of a social media campaign may increase with the support from people of a high net worth, independent of age or sex.

\section{Limitations of this study}

We had limited power to detect differences in $\mathrm{R}_{0}$ for personal factors as the inclusion criteria restricted the number of eligible index cases. Reporting of the Ice Bucket Challenge might have been socially patterned, contributing to potentially biased associations between transmissibility and net worth. The epidemiological assessment is based on a non-representative sample, and generalisability to other population groups is limited. We did not account for the likely broader influence ${ }^{19}$ of our cohort of global celebrities on the much larger population of fans and followers worldwide (average of 6.5 million Facebook likes per cohort participant), thus underestimating the overall $\mathrm{R}_{0}$, analogous to the "super spreader" concept. ${ }^{20}$

We thank Y Yuan, CKL Yiu, and T Li for their contributions to the data collection (which we hope provided some entertainment) and the illustration of the Christmas trees.

Contributors: MYN conceived the study, wrote the initial protocol, collected data, and wrote the first draft of the manuscript. BHYC developed the protocol and collected data. EHYL, HP, MYN, and GML analysed and interpreted the data. All authors critically revised the final manuscript, had access to the full dataset, take responsibility for the integrity of the data and the accuracy of the dataset, and gave final approval for the submission of this version for consideration of publication. EHYL and HP contributed equally to the work. MYN and $\mathrm{BHYC}$ are guarantors for the study.

Funding: This study received no external funding.

Competing interests: All authors have completed the ICMJE uniform disclosure form at www.icmje.org/coi_disclosure.pdf (available on request from the corresponding author) and declare: no support from any organisation for the submitted work; no financial relationships with any organisations that might have an interest in the submitted work in the previous three years; no other relationships or activities that could appear to have influenced the submitted work.

Ethical approval: Not required.

Data sharing: The dataset is available at the Dryad Digital Repository (provisional doi:10.5061/dryad.n4sc4).

Transparency: The lead author (MYN) affirms that this manuscript is an honest, accurate, and transparent account of the study being reported; that no important aspects of the study have been omitted; and that any discrepancies from the study as planned (and, if relevant, registered) have been explained.

1 ALS association. The Amyotrophic Lateral Sclerosis Association. 2014. www.alsa.org/. 2 Harford T. Ice bucket challenge: the cold facts. Financial Times 2014 Sep12.

3 Facebook newsroom. The Ice Bucket Challenge on Facebook. Facebook 2014 Sep 7. http://newsroom.fb.com/news/2014/08/the-ice-bucket-challenge-on-facebook/.

4 Broxton T, Interian Y, Vaver J, Wattenhofer M. Catching a viral video. J Intell Inf Syst 2013;40:241-59.

5 Jiang L, Miao Y, Yang Y, Lan Z, Hauptmann AG. Viral video style: a closer look at viral videos on YouTube. Proceedings of ACM International Conference on Multimedia Retrieval. Glasgow, United Kingdom, 2014:193-200.

6 Daley D, Kendal D. Stochastic rumors. J I Math App/ 1965;1:42-55

7 Anderson R, May R, Anderson B. Infectious diseases of humans: dynamics and control. Oxford University Press, 1992.

8 Roberts MG. The pluses and minuses of R0. J Roy Soc Interface 2007;4:949-61.

9 TIME. The 100 most influential people in the world. 2014. http://time.com/time100-2014

10 Editors of TIME. Great people of the 20th century. Time Life Education, 1998.

11 Celebrity Net Worth. CelebrityNetWorth.com. 2014. www.celebritynetworth.com.

12 Wolkewitz M, Allignol A, Graves N, Barnett AG. Is 27 really a dangerous age for famous musicians? Retrospective cohort study. BMJ 2011;343:d7799.

13 Johnson G, Guha I, Davies P. Were James Bond's drinks shaken because of alcohol induced tremor? BMJ 2013:347:f7255.

14 Giles J. Internet encyclopaedias go head to head. Nature 2005:438:900-1.

15 Stampler $L$. This is how many ice bucket challenge videos people have posted on Facebook. TIME2014 Aug 15. http://time.com/3117501/als-ice-bucket-challenge-videoson-facebook/.

16 Izadi E. Ice bucket challenge participants keep getting hurt. Washington Post 2014 Aug 28. www.washingtonpost.com/blogs/style-blog/wp/2014/08/28/ice-bucket-challengeparticipants-keep-getting-hurt-there-may-be-one-related-death-too/.

17 Altizer S, Dobson A, Hosseini P, Hudson P, Pascual M, Rohani P. Seasonality and the dynamics of infectious diseases. Ecol Lett 2006;9:467-84.

18 Centola D. The spread of behavior in an online social network experiment. Science 2010;329:1194-7.

19 Larson RJ, Woloshin S, Schwartz LM, Welch HG. Celebrity endorsements of cancer screening. J Natl Cancer / 2005:97:693-5.

20 Riley S, Fraser C, Donnelly CA, Ghani AC, Abu-Raddad LJ, Hedley AJ, et al. Transmission dynamics of the etiological agent of SARS in Hong Kong: impact of public health interventions. Science 2003;300:1961-6.

21 Vink MA, Bootsma MCJ, Wallinga J. Serial intervals of respiratory infectious diseases: a systematic review and analysis. Am J Epidemiol 2014;180:865-75.

22 Cauchemez S, Fraser C, Van Kerkhove MD, Donnelly CA, Riley S, Rambaut A, et al. Middle East respiratory syndrome coronavirus: quantification of the extent of the epidemic, surveillance biases, and transmissibility. Lancet Infect Dis 2014;14:50-6.

23 Poletto C, Pelat C, Lévy-Bruhl D, Yazdanpanah Y, Boëlle P, Colizza V. Assessment of the Middle East respiratory syndrome coronavirus (MERS-CoV) epidemic in the Middle East and risk of international spread using a novel maximum likelihood analysis approach. Euro Surveill 2014:19:1-10.

24 Breban R, Riou J, Fontanet A. Interhuman transmissibility of Middle East respiratory syndrome coronavirus: estimation of pandemic risk. Lancet 2013;382:694-9.

25 Assiri A, McGeer A, Perl TM, Price CS, Al Rabeeah AA, Cummings DAT, et al. Hospital outbreak of Middle East respiratory syndrome coronavirus. N Engl J Med 2013;369:407-16.

26 Gay NJ. The theory of measles elimination: implications for the design of elimination strategies. J Infect Dis 2004;189:S27-35.

Accepted: 17 November 2014

\section{Cite this as: BMJ 2014;349:97185}

This is an Open Access article distributed in accordance with the Creative Commons Attribution Non Commercial (CC BY-NC 4.0) license, which permits others to distribute, remix, adapt, build upon this work non-commercially, and license their derivative works on different terms, provided the original work is properly cited and the use is non-commercial. See: http://creativecommons.org/licenses/by-nc/4.0/. 


\section{What is already known on the topic}

Numerous reports have suggested that the Ice Bucket Challenge has gone "viral" Until now formal analysis of its transmissibility has been limited

\section{What this study adds}

The Ice Bucket Challenge was moderately transmissible among global celebrities and their nominees

Higher net worth may be associated with greater transmissibility

\section{Tables}

Table 1| Personal information, individual R0, and total number of successful contacts of celebrities taking part in the Ice Bucket Challenge in each nomination chain up to fifth generation for each index case

\begin{tabular}{lclccc} 
Index case & Age (years) & \multicolumn{1}{c}{ Profession } & Net worth $\mathbf{( \$ 0 0 0 ~ 0 0 0 )}$ & $\mathbf{R}_{\mathbf{0}}{ }^{*}$ Total No of successful contacts \\
David Beckham & 39 & Sports & 350 & 3 & 10 \\
\hline Cristiano Ronaldo & 29 & Sports & 250 & 1 & 13 \\
\hline Benedict Cumberbatch & 38 & Artist & 15 & 2 & 7 \\
\hline Stephen Hawking & 72 & Scientist & 20 & 2 & 2 \\
\hline Mark Zuckerberg & 30 & Entrepreneur & 33300 & 3 & 41 \\
\hline Oprah Winfrey & 60 & Entrepreneur & 2900 & 3 & 20 \\
\hline Homer Simpson & Unknown & Nuclear safety inspector & Unknown & 1 & 1 \\
\hline Kermit the Frog & Unknown & Entertainer & Unknown & 1 & 1 \\
\hline
\end{tabular}

*Measure of transmissibility.

$\$ 1.00$ (£0.64; €0.81). 
Table 2| Association of personal characteristics with basic reproduction number* $(\mathbf{R} 0)$, in the celebrities based cohort of the Ice Bucket Challenge, 2014

\begin{tabular}{lc} 
Characteristics & Odds ratio $(95 \% \mathrm{Cl})$ \\
\hline Age (years) & $1.01(0.98$ to 1.04$)$ \\
\hline Female sex & $0.80(0.38$ to 1.68$)$ \\
\hline Occupational sector: & \\
\hline Arts & Reference \\
\hline Business & $2.23(0.89$ to 5.59$)$ \\
\hline Government & $1.39(0.11$ to 18.0$)$ \\
\hline Sports & $1.15(0.34$ to 3.93$)$ \\
\hline Science & $0.51(0.09$ to 3.10$)$ \\
\hline Log (net worth) & $1.63(1.06$ to 2.50$)$ \\
\hline Log (Facebook likes) & $1.23(0.87$ to 1.72$)$ \\
\hline Log (Twitter followers) & $1.46(0.96$ to 2.22$)$ \\
\hline
\end{tabular}

${ }^{*}$ Measure of transmissibility. 
Table 3| R0 (major determinant of size of epidemic) of Ice Bucket Challenge and other contagions

\begin{tabular}{lccc} 
Contagion & Period of event/outbreak & $\mathbf{R}_{\mathbf{0}}$ & Mean serial interval (days) \\
\hline Ice Bucket Challenge* & 2014 & 1.43 & $2.1 \dagger$ \\
\hline Pandemic influenza & 2009 & $1.2-2.3^{21}$ & $2.8^{21}$ \\
\hline MERS-CoV & $2012-14$ & $0.5-1.3^{22-24}$ & $9.67^{25}$ \\
\hline Measles & Recurring & $14-18^{26}$ & $11.7^{21}$ \\
\hline Smallpox & Before 1980, eradicated & $4-10^{7}$ & $17.7^{21}$ \\
\hline
\end{tabular}

MERS-CoV=Middle East respiratory syndrome coronavirus.

$R_{0}$ values $>1$ represent a self sustaining epidemic.

*Based on data in current study only.

†Median serial interval was 1 day.

‡Derived mean from fitted log normal distribution. 


\section{Figure}

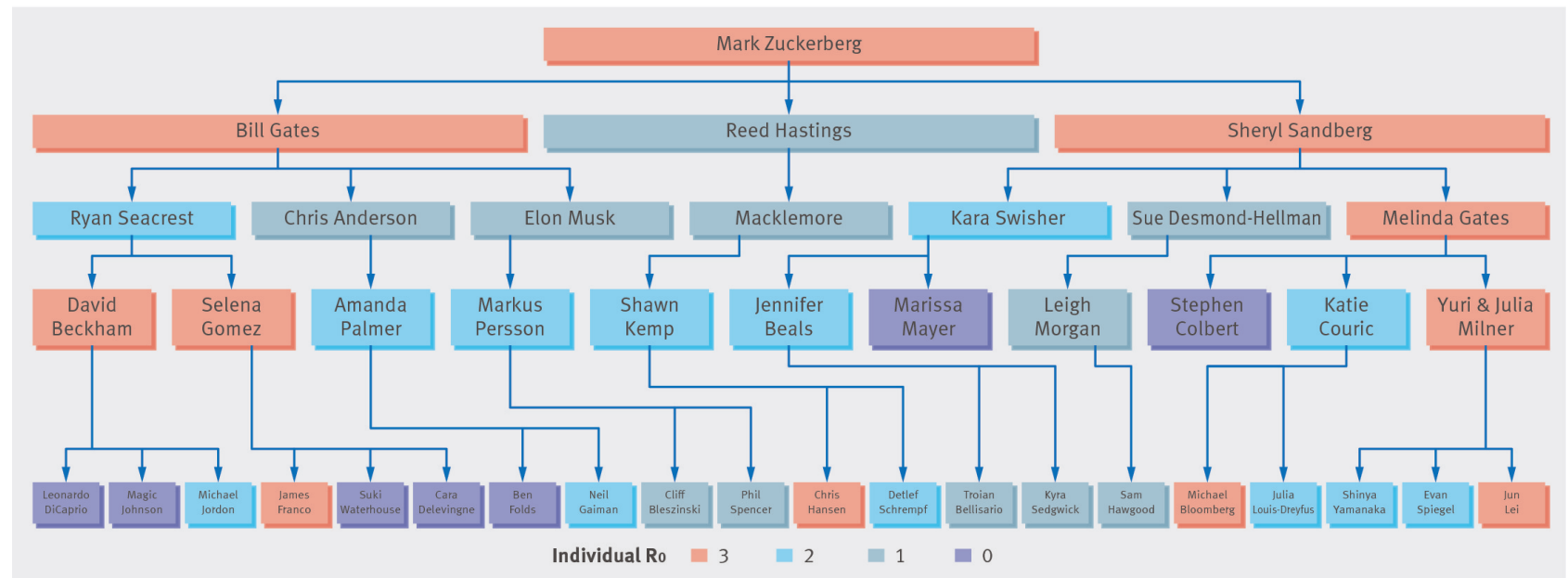

Tree structure of nominations associated with index case Mark Zuckerberg 